This item was submitted to Loughborough's Research Repository by the author.

Items in Figshare are protected by copyright, with all rights reserved, unless otherwise indicated.

\title{
Transformational leadership and depressive symptoms: a prospective study
}

\section{PLEASE CITE THE PUBLISHED VERSION}

http://dx.doi.org/10.1016/j.jad.2009.03.020

\section{PUBLISHER}

(c) Elsevier

VERSION

AM (Accepted Manuscript)

\section{LICENCE}

CC BY-NC-ND 4.0

\section{REPOSITORY RECORD}

Munir, Fehmidah, Karina Nielsen, and Isabella G. Carneiro. 2019. "Transformational Leadership and Depressive Symptoms: A Prospective Study”. figshare. https://hdl.handle.net/2134/10431. 
This item was submitted to Loughborough's Institutional Repository (https://dspace.lboro.ac.uk/) by the author and is made available under the following Creative Commons Licence conditions.

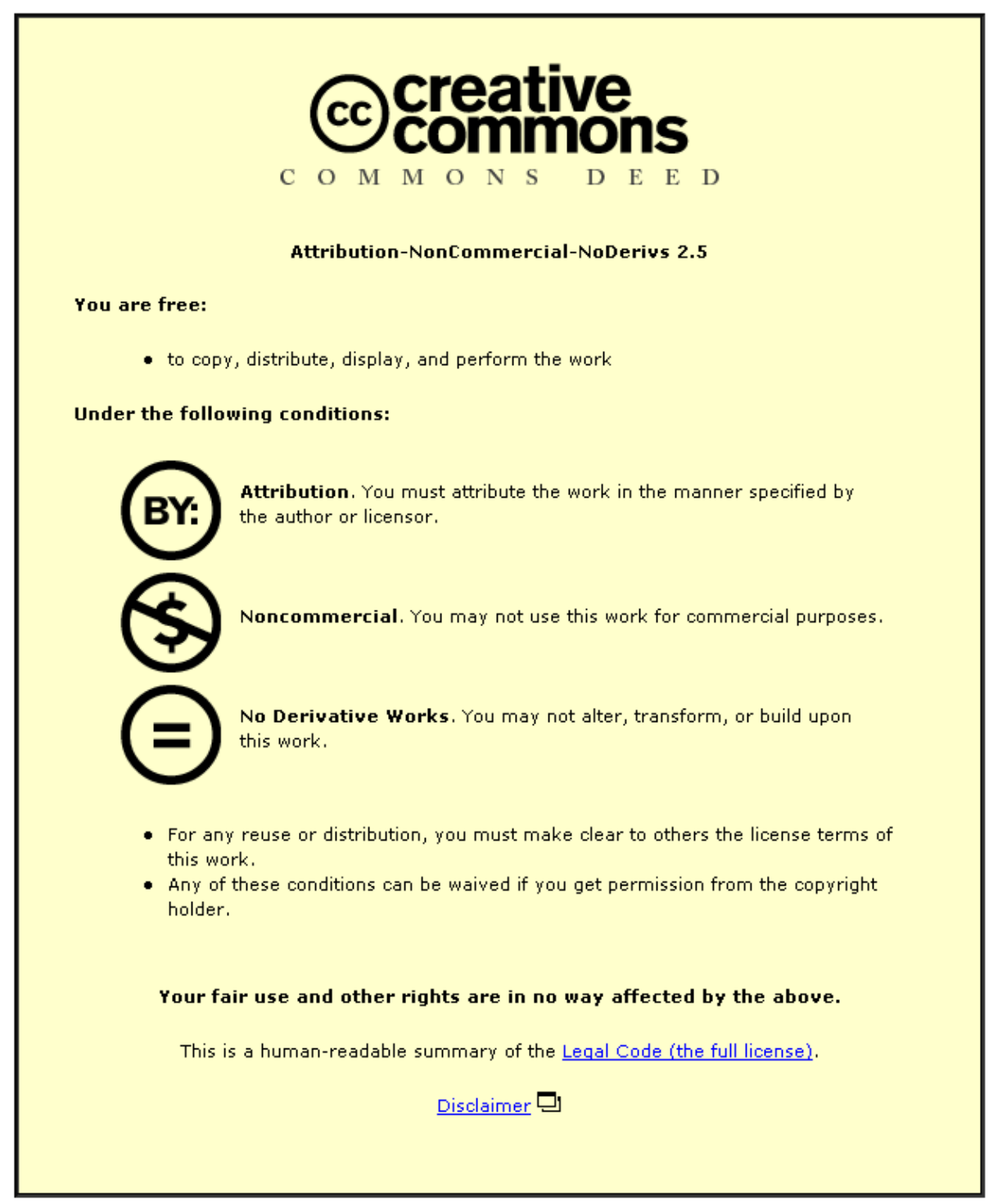

For the full text of this licence, please go to: http://creativecommons.org/licenses/by-nc-nd/2.5/ 


\title{
Transformational leadership and depressive symptoms: A prospective study
}

PUBLISHED IN: Journal of Affective Disorders, 2010, 235-239.

\author{
Fehmidah Munir ${ }^{a}$, Karina Nielsen ${ }^{\mathrm{b}}$, Isabella Gomes Carneiro ${ }^{\mathrm{b}}$, \\ ${ }^{a}$ Department of Human Sciences, Loughborough University, Loughborough, \\ Leicestershire, LE11 3TU, United Kingdom \\ ${ }^{\mathrm{b}}$ National Research Centre for the Working Environment, Lersoe Park Alle 105, DK - \\ 2100 Copenhagen, Denmark
}

Abstract

Objective: The aim of this study was to examine the association between

transformational leadership and depressive symptoms in employees working within healthcare.

Method: 447 employees completed a baseline survey and 274 completed a followup survey 18 months later. 188 completed both baseline and follow-up survey. Transformational leadership was measured using the Global Transformational Leadership Scale and depression was measured using with the Major Depression Inventory.

Results: Transformational leadership was negatively associated with depressive symptoms at baseline $(\beta=-0.30, p<.001,9 \%$ variance $)$ follow-up $(\beta=-0.27, p<.001,7 \%$ variance $)$ and prospectively $(\beta=-0.23, p<.004,5 \%$ variance $)$.

Conclusion: Managers with a transformational leadership style may help toward protecting employees from developing major depression. 
Keywords: transformational leadership, depression, work stress, well-being

Running title: Transformational leadership and depression 
Clinical significance

This paper contributes new knowledge in the importance of transformational leadership in managing depressive symptoms among employees, particularly in those working in stressful occupations (i.e. healthcare). Transformational leadership behaviors can be trained and occupational health professionals have an important role to play in promoting the benefits of transformational leaders.

Word count: 49 
Introduction

Depression is considered to have a significant impact on employment and work productivity (Wang et al., 2004). A number of non-modifiable risk factors associated with depression include genetics, female gender, poor parenting, certain personality traits and early onset anxiety (Kendler et al., 2002; Kendler et al, 2006). Modifiable risk factors for depression are largely psychosocial and include poverty, education, access to healthcare (Beardslee and Gladstone, 2001), substance misuse, low selfefficacy and low social support (Kendler et al., 2006). It is well-established that work characteristics such as high work demands, low level of decision latitude, poor work life balance and job insecurity can contribute to the onset of depression (Bonde, 2008; Couser, 2008; Netterstrøm, Conrad, Bech, Fink, Olsen, Rugulies \& Stansfeld, 2008).

There is strong evidence that supervisor support has a beneficial effect on health outcomes among employees, particularly for depression (Dormann and Zapf, 1996; Kawakami et al., 2005). It has been associated with lower sickness absence related to depression (Stansfield et al, 1997), and a decrease in risk for future depression (Netterstrøm et al., 2008).It is therefore evident that good supervisory leadership and managerial skills are important in the reduction of depression (Kuoppala et al., 2008). One leadership style influential in improving the health and well-being of workers, is transformational leadership (Nielsen et al., 2008a). Transformational leaders employ a visionary and creative style of leadership. They act as a coach and mentor, provide personal attention and psychosocial support to the development of the individual employee, and inspire employees to make independent decisions, and reach satisfaction in their work (Bass, 1985; Bass, 1999; Sosik and Godshalk, 2004). Links have been established between transformational leadership styles and improved general well-being (Nielsen et al, 2008b), reduced burnout (Seltzer et al, 1989; Corrigan et al., 2007; Hetland et al, 2007), and lower job-related stress (Sosik and 
Godshalk, 2000). Although measures of well-being and burnout in these studies often include symptoms of depression, to our knowledge, there are no studies on transformational leadership that have measured depression. We propose that transformational leadership may be negatively associated with depression as transformational leaders make employees feel valued and better equipped to cope with job demands as their situation is taken into account. Transformational leaders also promote a positive vision of the future which may help employees see their situation in a brighter light (Sivanathan et al., 2004).

The present study aims to investigate the impact of transformational leadership behaviors on symptoms of depression among a cohort of Danish healthcare workers. Depression and stress are highly prevalent among healthcare occupations (Wieclaw et al, 2005), and particularly among females (Kendler et al., 2002), who represent a significant proportion of healthcare workers (Wieclaw et al, 2006). We analysed the associations between transformational leadership style and depression, both in a cross-sectional sample and in a prospective cohort, allowing us to compare the magnitude of these relationships in two different study designs. We hypothesized that transformational leadership behaviours is associated with lower depression symptoms at baseline; at follow-up (18 months) and prospectively (that baseline levels of transformational leadership is associated with lower depression symptoms at follow-up.

\section{Materials and Methods}

The sample consisted of elderly care staff working in a large Danish local government. Staff included cleaning personnel, canteen personnel, healthcare assistants, nurses, physiotherapists, and maintenance staff. Each occupational group had a formal leader with managerial responsibilities; this was the manager participants were asked to rate. 
At baseline, questionnaires were distributed to 551 eligible staff out of which 447 completed and returned questionnaires (response rate 81\%). At follow-up (18 months later) questionnaires were distributed to 521 staff and 274 were returned (response rate 53\%). As questionnaires were sent to all employees working at the elderly care centers, new employees $(n=92)$ were included in the follow-up survey.

\section{Measures}

Transformational leadership was measured using the Global Transformational Leadership Scale (Carless et al; 2000). It consists of seven items that have a high degree of convergent validity with more established lengthier questionnaires such as the MLQ and the LPI (Carless et al., 2000). An example item is: "My leader encourages thinking about problems in new ways and questions assumptions". Response categories were: 1 = To a very large extent, $2=$ To a large extent, $3=$ Somewhat, 4 = To a small extent, $5=$ To a very small extent. Cronbach's alpha at time 1 was .90 , and .94 at time 2 .

Depressive symptoms was measured using the Major Depression Inventory (MDI); Bech et al., 2001). This consists of 10 items covering the ICD-10 and DSM-IV symptoms of depression with good reported reliability and validity (sensitivity 0.86 to 0.92 ; specificity 0.82 to 0.86$)$. An example item is: "Have you lost interest in your daily activities?" . Each items is measured on a six-point Likert scale (from 'all the time' to 'at no time'). The MDI can be used a measuring instrument using the total score (score ranging from 0 to 50 ), or it can be used as a diagnostic instrument. Demographic measures We included age, gender, cohabitation, number of dependents, occupational status, tenure. 
Statistics

SPSS version 14.0 (SPSS Inc., Chicago, IL) was used for all analyses. Correlation analyses were run for all variables. Three separate multiple regression analyses were performed: baseline analyses of transformational leadership and depressive symptoms ( $n=447$ ), follow-up analyses of transformational leadership and depressive symptoms $(n=274)$, and prospective analyses of baseline transformational leadership behaviors and follow-up depressive symptoms $(n=188)$. The latter regression analysis was conducted in order to assess whether transformational leadership behaviors protected against depressive symptoms over time. For covariates, we included age, gender, length of employment (tenure), and family status. These variables have been found to be associated with depression. Statistical significance was set at $p<.05$.

\section{Results}

Table 1 reports the demographic profile of participants at baseline, follow-up and those who participated at both baseline and follow-up. Overall, participants were predominantly female. The majority of staff were healthcare assistants (61-65\%), nurses were the next largest group (10-12\%), followed by $18-21 \%$ who had other health-related educations. The remaining participants had no healthcare-related education. In order to compare the differences between the samples, we looked at the demographic profiles of the 188 participants who provided data at both baseline and at follow-up. As can be seen in table 1, their demographic profile was representative of the full sample at both time points. Due to loss to follow-up, mean differences between the depression score were compared between the different samples. T-tests showed no significant differences in the depression score $(\mathrm{t}(346)=$ 1,75, $p<.05)$. 
Results from the separate linear regression analyses are presented in Table 3. For all three regression models, transformational leadership is negatively associated with depression symptoms. At baseline, transformational leadership explained $8 \%$ of the variance in reduced depressive symptoms; and explained 3\% of the variance at follow-up. The final regression analyses tested the prospective relationship between transformational leadership behaviors at baseline with depressive symptoms at follow-up. Transformational leadership explained $4 \%$ of the variance.

\section{Discussion}

The present study indicates that transformational leadership style is associated with reduced depressive symptoms both cross-sectionally and prospectively. The findings lend support to the growing literature on the benefits of managers and supervisors adopting a more transformational leadership style (Sivanathan et al., 2004). The findings also lend support to the literature on the beneficial effects of workplace social support on reducing the risk of depression (Kawakami et al., 2005; Park et al., 2004; Stansfield et al, 1997). Transformational leaders influence mentoring functions by providing psychosocial support and career development (Sosik and Godshalk, 2004), which can protect against poor well-being (Nielsen et al., 2008a; Nielsen et al., 2008b), work-related stress (Sosik and Godshalk, 2000), and burnout (Seltzer et al., 1989; Corrigan et al., 2007; Hetland et al, 2007). Our results contribute to this literature in that transformational leadership styles may also help toward reducing depressive symptoms and potentially protect employees from developing major depression. A further strength of our study is that by using a prospective design, we are able to provide more efficient estimators of the relationship between transformational leadership and depressive symptoms than cross-sectional studies. However, at follow-up and prospectively the variance explained by transformational leadership was slightly lower than at baseline. A possible explanation for this may be 
that organizational changes or pressures occurred at follow-up which were not measured in this study, and which may have reduced the protective effects of transformational leadership. . Further longitudinal and intervention studies are required to examine these possibilities.

There are several limitations to this study. First, the present study employed a questionnaire rather than a diagnostic interview to measure depression. However, studies have shown that the MDI is a reliable tool for measuring depression that can be scored both according to the DSM-IV and the ICD-10 algorithms for depressive symptomatology (Bech et al., 2001). Nevertheless, future studies should incorporate a more objective or clinical diagnosis of depression. A second limitation is the somewhat low variances explained by transformational leadership, however, these are not surprising considering the number of factors that contribute to, or protect against depression. These include age, gender, tenure, and partner/family status. However, none of these were associated with depression in this sample which may be due to the small sample size and gender bias (female). Personality traits may also play a role and research suggests that employees high in neuroticism and low in agreeableness may be less open to transformational leadership behaviors (Hetland, Sandal \& Johnsen, 2008). Positive health behaviours e.g. healthy eating and exercising may protect against the onset of depression and initiatives such as counselling and Cognitive Behavioral Therapy may alleviate depression (see Couser, 2008) in addition to the managers' leadership style. Other factors in the working environment have been found to contribute to depression (Bonde, 2008; Netterstrøm et al, 2008). Taken together, the vast number of other factors influencing depression are likely to impact the variance explained by transformational leadership.. Another limitation is that this study employed one single scale of transformational leadership subcomponents (Carless et al, 2000); this is not an unusual procedure as the four aspects of transformational leadership are highly correlated (Avolio and Bass, 1995). 
Future studies should examine whether the sub-components of transformational leadership exhibit direct effects on depression over time

Although this study employed a longitudinal perspective, the results are based on self-report data which means that common method and common source bias may pose a threat to our results (Podaskoff and MacKenzie, 2003). We used several methods to minimize such bias both in data collection and data analyses such as ensuring respondent confidentiality and counterbalancing questionnaire items. Another limitation of this study is that the sample worked within elderly care, where the majority of workers were healthcare assistants and therefore the findings from this study cannot be generalised to other settings. However, included all staff employed at the elderly care centres including maintenance, canteen and cleaning staff. We believe this has strengthened our results. It has been suggested that transformational leadership play a vital role in healthcare (Sofarelli and Brown, 1998; Thyer 2003; Murphy, 2005) particularly as stress and depression are reported to be highly prevalent in healthcare occupations (Wieclaw et al., 2005). Large numbers of studies on transformational leadership are therefore conducted in healthcare settings, and our findings contribute to this literature. Bass (1999) concluded that transformational leadership is relevant at all levels and all sectors. Therefore these links should be explored in other settings in order to test the replicability of our results.

To conclude, the study findings suggest that transformational leadership style is prospectively associated with reduced depressive symptoms. Further studies are warranted to examine these relationships in other occupational settings and include more appropriate covariates. As line managers can be trained in and educated to identify and manage employees with depressive symptoms (Langlieb and DePaulo, 2008) they can also be trained in transformational leadership behaviors (Barling et 
al., 1996; Parry and Sinha, 2005). Future studies should include appropriate interventions to examine the effectiveness of transformational leadership in reducing depressive symptoms and potentially protecting against major depression.

Acknowledgements 


\section{References}

Avolio BJ, Bass BM., 1995 Individual consideration reviewed at multiple levels of analysis: A multi-level framework for examining the diffusion of transformational leadership. Leadership Quart. 6, 199-218.

Bass BM., 1987. Leadership beyond expectations. New York: Free Press; 1985.

Bass BM. Two decades of research and development in transformational leadership. Eur J Work Org Psych. 8, 9-32.

Bass BM, Avolio J, Goldheim L., 1987. Biography and the assessment of leadership at the world-class level. J Manag. 13, 7-19.

Barling J, Weber T, Kelloway K., 1996. Effects of transformational leadership training on attitudinal and financial outcomes: A field experiment. J Applied Psychol. 81, 827832.

Beardslee WR, Gladstone TR., 2001. Prevention of childhood depression: recent findings and future prospects. Biol Psychiatry. 49, 1101-1110.

Bech P, Rasmussen N-A, Raabaek Olsen L, Noerholm V, Abildgaard W., 2001. The sensitivity and specificity of the Major Depression Inventory, using the Present State Examination as the index of diagnostic validity. J Affect Dis. 66, 159-164.

Bonde, J.P.E. (2008). Psychosocial factors and risk of depression: a systematic review of the epidemiological evidence. Occup Environ Med 65, 438-445.

Carless S, Wearing A, Mann L., 2000. A short measure of transformational leadership. J Business Psychol. 14, 389-405.

Corrigan PW, Diwan S, Campion J, Rashid F., 2007. Transformational leadership and the mental health team. Adm Policy Mental Health. 30, 97-108.

Couser GP. , 2008. Challenges and opportunities for preventing depression in the workplace: A review of the evidence supporting workplace factors and interventions. J Occup Environ Med. 50, 411-427.

Cox T., 1994. Stress research and stress management: putting theory to work. Sudbury: Health \& Safety Executive. 
Dormann C, Zapf D., 1999. Social support, social stressors at work, and depressive symptoms: testing for main and moderating effects with structural equations in a three-wave longitudinal study. J Appl Psychol. 84, 874-884.

Hetland H, Sandal GM, Johnsen TB., 2007. Burnout in the information technology sector: Does leadership matter? Eur J Work Org Psychol. 16, 58-75.

Hetland H, Sandal GM, Johnsen, TB. 2008. Followers' personality and leadership. J Leadership Org Studies, 14, 322-331.

Jenkins R, Harvey S, Butler T, Thomas RL., 1996. Minor psychiatric morbidity, its prevalence and outcome in a cohort of civil servants--a seven-year follow-up study. Occup Med. 46, 209-215.

Judge T, Piccolo RF., 2004. Transformational and transactional leadership: A metaanalytic review of their relative validity. J Applied Psychol. 89, 755-768.

Karasek, R., 1979. Job demands, job decision latitude and mental strain: Implications for job redesign. Adm Sci Q. 24, 285-306.

Kawakami N, Araki S, Kawashima M.,1990. Effects of job stress on occurrence of major depression in Japanese industry: a case-control study nested in a cohort study. J Occup Med. 32, 772-775

Kawakami N, Kobayashi Y, Takao S, Tsutsumi A., 2005. Effects of web-based supervisor training on supervisor support and psychological distress among workers: A randomised controlled trial. Prev Med. 41, 471-478.

Kendler KS, Gardner CO, Prescott CA., 2002. Toward a comprehensive developmental model for major depression in women. Am J Psychiatry. 159, 1133-1145.

Kendler KS, Gardner CO, Prescott CA., 2006. Toward a comprehensive developmental model for major depression in men. Am J Psychiatry. 163, 115-124.

Kuoppala J, Lamminpää A, Liira J, Vainio H., 2008. Leadership, job well-being, and health effects - a systematic review and a meta-analysis. J Occup Environ Med. 50, 904-915. 
Langlieb AL, DePaulo JR., 2008 Etiology of depression and implications on work environment. J Occup Environ Med. 50, 391-395.

Murphy L., 2005. Transformational leadership: a cascading chain reaction. J Nurs Manag. 13, 128-136.

Netterstrøm Bo, Conrad N, Bech P, Fink P, Olsen O, Rugulies R, Stansfield S., 2008. The relation between work-related psychosocial factors and the development of depression. Epidem Rev. 30, 118-132.

Nielsen K, Yarker J, Brenner S-O, Randall R., 2008a The importance of transformational leadership style for the well-being of employees working with older people. J Adv Nurs, 63, 165-175.

Nielsen K, Randall R, Yarker J, Brenner S-O., 2008b. The effects of transformational leadership on followers' perceived work characteristics and psychological well-being: A longitudinal study. Work Stress. 22, 16-32.

Park KO, Wilson MG, Lee MS., 2004 Effects of social support at work on depression and organizational productivity. Am J Health Behav. 28, 444-455.

Parry KW, Sinha PN., 2005. Researching the trainability of transformational organisational leadership. Human Resourc Dev Int. 8, 165-183.

Podaskoff PM, MacKenzie SB, Lee J., 2003. Common method biases in behavioural research: A critical review of the literature and recommended remedies. J Applied Psychol. 88, 879-903.

Seltzer J, Numerof R, Bass B., 1989. Transformational leadership: Is it a source of more burnout and stress? J Health Human Resour Adm. 174-185.

Sofarelli D, Brown D., 1998. The need for nursing leadership in uncertain times. J Nurs Manag. 6, 201-207.

Sosik JJ, Godshalk VM., 2004. Self-other rating agreement in mentoring: meeting protégé expectations for development and career advancement. Group Org Manag. 29, 442-469. 
Sosik J, Godshalk V., 2000. . Leadership styles, mentoring functions received, and jobrelated stress: a conceptual model and preliminary study. J Org Behav. 21, 365-390.

Stansfield SA, Fuhrer R, Head J, Ferrie J, \& Shipley M., 1997. Work and Psychiatric disorder in the Whitehall II study. J Psychosom Res. 43, 73-81

Thyer G., 2003. Dare to be different: transformational leadership may hold the key to reducing nursing shortage. J Nurs Manag. 11, 73-79.

Tsutsumi A, Kawakami N., 2004. A review of empirical studies on the model of effortreward imbalance at work: reducing occupational stress by implementing a new theory. Soc Sci Med. 59, 2335-2359.

Waldenström K, Ahlberg G, Bergman P, Forsell Y, Stoetzer U, Waldenström M, Lundberg I., 2008. Externally assessed psychosocial work characteristics and diagnosis of anxiety and depression. Occup Environ Med. 65, 90-97.

Wang PS, Beck AL, Berglund PD, McKenas DK, Pronk NP, Simon GE, Kessler RC. , 2004. Effects of major depression on moment-in-time work performance. Am J Psychiatry. 161, 1885-1891.

Wieclaw J, Agerbo E, Mortensen PB, Bonde JP., 2005. Occupational riskof affective and stress-related disorders in the Danish workforce. Scand J Work Environ Health. 31, 343-351.

Wieclaw J, Agerbo E, Mortensen PB, Bonde JP., 2006. Risk of affective and stress related disorders among employees in human service professions. Occup Environ Med. 63, 314-319. 
Table 1: Participant demographics

\begin{tabular}{|c|c|c|c|c|c|c|c|c|c|c|c|c|}
\hline & \multicolumn{4}{|c|}{ Baseline sample } & \multicolumn{4}{|c|}{ Follow-up sample } & \multicolumn{4}{|c|}{$\begin{array}{l}\text { Prospective sample (baseline } \\
\text { and follow-up) }\end{array}$} \\
\hline & $N$ & $\%$ & $M$ & $S D$ & $N$ & $\%$ & $M$ & $S D$ & $N$ & $\%$ & $M$ & $S D$ \\
\hline Response rates & 447 & 81.1 & & & 274 & 52.6 & & & 188 & 34.1 & & \\
\hline Age & & & 43.8 & 11.1 & & & 44.5 & 10.9 & & & 45.0 & 9.9 \\
\hline Gender (\% women) & 416 & 93.0 & & & 249 & 90.9 & & & 110 & 58.5 & & \\
\hline Tenure (in years) & & & 11.6 & 10.2 & & & 7.6 & 7.8 & & & 9.0 & 7.7 \\
\hline Healthcare assistants & 277 & 62.0 & & & 178 & 65.0 & & & 115 & 61.2 & & \\
\hline Nurses & 54 & 12.1 & & & 27 & 9.9 & & & 23 & 12.2 & & \\
\hline $\begin{array}{l}\text { Other healthcare- } \\
\text { related education }\end{array}$ & 80 & 17.9 & & & 52 & 19.0 & & & 39 & 20.7 & & \\
\hline $\begin{array}{l}\text { No healthcare-related } \\
\text { education }\end{array}$ & 37 & 8.3 & & & 16 & 5.8 & & & 15 & 8.0 & & \\
\hline
\end{tabular}


Table 2: Mean, Standard deviations, and correlations among study variables

\begin{tabular}{|c|c|c|c|c|c|c|c|}
\hline & \multirow[t]{2}{*}{ Variable } & \multirow[t]{2}{*}{$M$} & \multirow[t]{2}{*}{$S D$} & \multicolumn{4}{|c|}{ Correlations } \\
\hline & & & & 1 & 2 & 3 & 4 \\
\hline 1 & $\begin{array}{l}\text { Transformational } \\
\text { leadership baseline }\end{array}$ & 59.1 & 20.6 & - & & & \\
\hline 2 & $\begin{array}{l}\text { Transformational } \\
\text { leadership follow-up }\end{array}$ & 61.9 & 20.3 & $0.47^{* \star}$ & - & & \\
\hline 3 & Depression baseline $^{a}$ & 2.5 & 1.2 & -0.30 ** & $-0.21^{*}$ & - & \\
\hline 4 & Depression follow-up ${ }^{a}$ & 2.4 & 1.2 & $-0.23^{\star \star}$ & $-0.27^{\star *}$ & $0.62^{\star \star}$ & - \\
\hline
\end{tabular}


Table 3: Multiple regression analysis of transformational leadership with depressive symptoms as the dependent variable (baseline, follow-up and prospective).

\begin{tabular}{|c|c|c|c|c|c|c|c|c|c|}
\hline \multirow[t]{2}{*}{ Variable } & \multicolumn{3}{|c|}{$\begin{array}{l}\text { Analysis } 1 \\
\text { Baseline } \\
(n=447)\end{array}$} & \multicolumn{3}{|c|}{$\begin{array}{c}\text { Analysis } 2 \\
18 \text { months follow-up } \\
(n=274)\end{array}$} & \multicolumn{3}{|c|}{$\begin{array}{c}\text { Analysis } 3 \\
\text { Prospective (baseline to follow-up) } \\
(n=188)\end{array}$} \\
\hline & B & SE & $\beta$ & B & SE & $\beta$ & B & $S E$ & $\beta$ \\
\hline Age & 0.00 & 0.00 & 0.00 & 0.01 & 0.01 & 0.11 & 0.01 & 0.01 & 0.11 \\
\hline Gender & 0.38 & 0.34 & 0.08 & -0.44 & 0.42 & -0.10 & -0.44 & 0.42 & -0.10 \\
\hline Tenure & -0.01 & 0.01 & -0.07 & -0.01 & 0.01 & -0.10 & -0.01 & 0.01 & -0.10 \\
\hline Cohabiting & -0.07 & 0.20 & -0.03 & -0.18 & 0.26 & -0.07 & -0.18 & 0.25 & -0.07 \\
\hline Children at home & 0.06 & 0.08 & 0.05 & .0 .05 & 0.11 & 0.04 & .0 .05 & 0.11 & 0.04 \\
\hline R² (adjusted) & -0.01 & & & -0.01 & & & -0.01 & & \\
\hline \multicolumn{10}{|l|}{ Step 2} \\
\hline $\begin{array}{l}\text { Transformational } \\
\text { leadership baseline }\end{array}$ & -0.02 & 0.01 & $-0.31^{\star \star}$ & - & - & - & -0.01 & -0.01 & $-.21^{*}$ \\
\hline $\begin{array}{l}\text { Transformational } \\
\text { leadership follow-up }\end{array}$ & - & & & -0.01 & -0.01 & $-0.25^{\star \star}$ & & & \\
\hline $\mathrm{R}^{2}$ (adjusted) & .08 & & & .03 & & & .04 & & \\
\hline
\end{tabular}

${ }^{*} p<.05 ;{ }^{* \star} p<.01$ 